676

\title{
はく離せん断層における渦度の消失*
}

\author{
宮 越 勝 美*1, 羽二生 博之*1, 金 相 —*2 \\ 高井和 紀 $^{* 1}$, Mohammad Rofiqul ISLAM*3
}

\section{Decay of Vorticity in Separated Shear Layer}

\author{
Katsumi MIYAKOSHI, Hiroyuki HANIU*4, Sangil KIM, \\ Kazunori TAKAI and Mohammad Rofiqul ISLAM \\ ${ }^{* 4}$ Department of Mechanical Engineering, Kitami Institute of Technology,
} 165 Koen-cho, Kitami-shi, Hokkaido, 090-8507 Japan

\begin{abstract}
In this study, process of vorticity decay caused by viscous interaction in a separated shear layer was investigated based on velocity measurements and flow visualization of the separated shear layer in the very vicinity of the separation point of a test body. A right isosceles triangular prism with two $200 \mathrm{~mm}$ long isosceles sides was used as the test body, and the experiment was carried out at the fixed Reynolds number of 19000 . As the results, following aspects were clarified about the vorticity decay. i ) A part of the vorticity decay in the separated share layer behind a body was caused by viscous interaction associated with transition of velocity distribution from boundary layer like shape to free shear layer like shape in the very vicinity of the separation point. ii) The Reynolds shear stress associated with turbulent dissipation does not take part in the vorticity decay process in the very vicinity of the separation point. iii) Since the Reynolds shear stress about an intermediate size vortex produced by coalescence of smaller vortices was considerably large, the flow field becomes turbulent and three dimensional by the coalescence of the smaller vortices.
\end{abstract}

Key Words: Shear Flow, Separation, Viscous Flow, Flow Measurements, Flow Visualization, Vorticity Decay, Transition

\section{1. 緒 論}

流れの中に置かれた物体の後方に渦が形成されて物 体に変動流体力が作用するため，我々の身近で多くの 弊害がもたらされている。例えば橋やビルなどに振動 や騒音を引き起こしたり，高速増殖炉(1995, 日本)の 事故のように物体が共振して破壊が起こるなどの事例 が報告されている。

これらの弊害を引き起こす変動流体力には物体後方 における渦の循環が一つの要因とされており，循環に は㓦離せん断層に放出される渦度の連行や消失が深く 関わっている。これらの研究は Gerrard(1)やSarpkaya-Schoaff ら (2)によって報告されているほか, Mair-Maull ら(3) は鈍い物体からのカルマン渦の放出 に括いて，一方の剥離せん断層の持つ循環のうち約 15\%がもう一方の剥離せん断層から連行された循環に よって相殺され，渦度の消失を起こすと報告してい

* 原稿受付 2008 年 8 月 21 日.

*1 正員, 北見工業大学機械工学科(恶090-8507 北見市公園町 $165)$

*22 正員, アイシン精機 (株) (焉 448-8650 邚谷市朝日町 2-1).

*3 Rajshahi University of Engineering and Technology (Rajshahi 6204, Bangladesh).

E-mail : harry@mail.kitami-it.ac.jp
る。しかし, 物体後方における剝離せん断層の愿さが 薄く，この付近における速度ベクトルの時間変化が激 しいため，定量的に調べた報告はあまりないのが現状 である。

Luo ら ${ }^{(4)}$ 扔よび Tong ${ }^{(5)}$ はレーザー流速計(LDV) を用いてレイノルズ数を変化させた時の四角柱後流の 循環，渦度，ストローハル数の変化を定量的に調べた。 Wang ら ${ }^{(6)}$ は壁面近傍に設置された円柱の後流の速 度分布，ストローハル数，レイノルズ応力，渦度，変動 エネルギーなどを円柱と壁面の間隔を変えて調べた。 また Downes ${ }^{(7)} ら は$ は流れの中にある片支持柱の流力 振動時の変位軌跡および軌跡各ポジションでの渦度を 調べている，しかしいずれの研究も物体の極近傍につ いては調べていない，羽二生ら(8)(9) は，LDVによっ て定量的に計測を行ない，物体剥離点の近傍における 渦度が急激に減少する領域では，せん断変形に基づく 粘性力が作用していると報告している。このことは， Mair-Maull ら ${ }^{(3)}$ が指摘した要因の他にも渦度の消失 の要因があり得ることを示唆しており，物体剥離点近 傍における剥離せん断層では，境界層的な速度分布か ら自由せん断流的な速度分布へと遷移する過程に扔け る粘性作用が関与していると考えることができる。 本研究では異符号渦度同士の混合による相殺で渦度 
の消失が起こらないように，三角柱を水路底面に設置 して，三角柱の上部頂点から剝離せん断層を形成させ た。また，羽二生ら ${ }^{(8)}$ の報告よりも測定領域の解像度 を格段に高めて, 薄い剝離せん断層の挙動を詳しく調 べるために，供試物体の代表寸法を 4 倍の大きさにし た。さらに LDVによる時間平均速度の測定領域も， 物体の代表長さに対して下流約 25\%付近であったも のから物体極近傍である下流約 4\%付近にて測定を行 つた。さらにこの測定領域において可視化実験も行 い, 物体豩離点の極近傍における渦度の消失が剝離せ ん断層の遷移過程や乱流拡散とどのように関与してい るかを調心゙た。

\section{2. 実験装置および方法}

本実験では測定部寸法が幅 $400 \mathrm{~mm}$, 深さ $890 \mathrm{~mm}$ の環流式開水路を用いた。供試物体には，剝離点が固

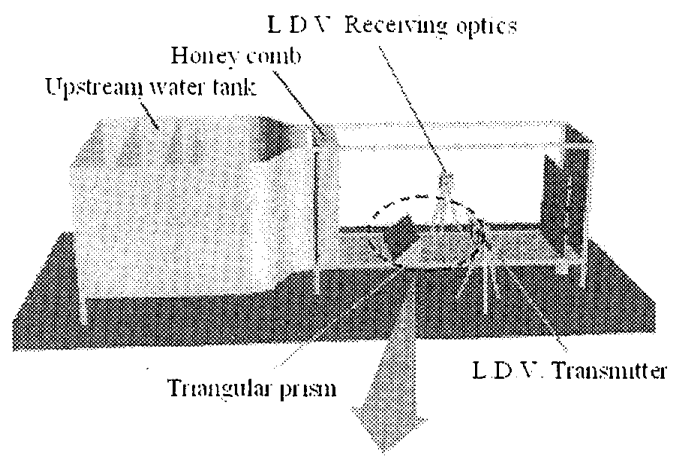

(a) Over view

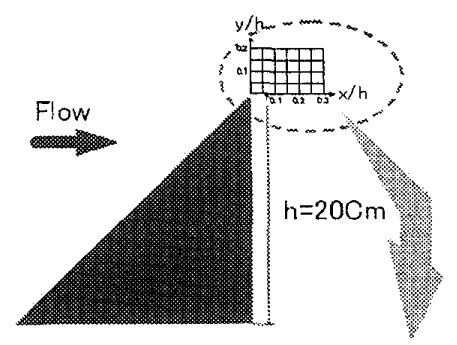

(b) Close up

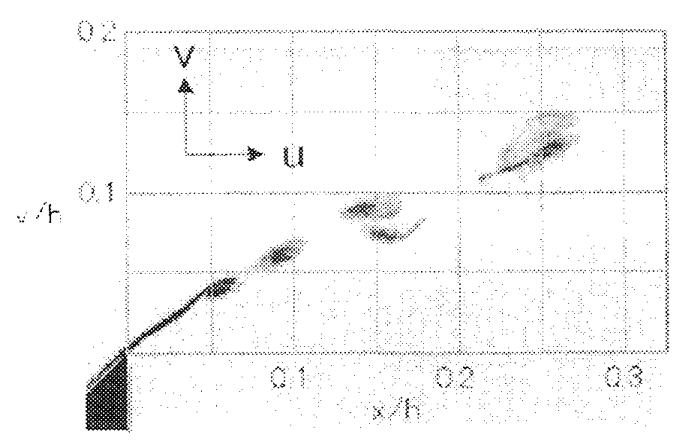

(c) Measurement area

Fig. 1 Experimental arrangement and definitions of symbols
定される断面(直角二等辺三角形) を有する三角柱を使 用し, 図 1(a)のように代表寸法 $h$ は $20 \mathrm{~cm}$ である. また三角柱のスパン方向中央部には $\phi 1 \mathrm{~mm} の$ 可視化 用色素流出孔が設けられている。

実験の測定に当たっては, 主流速度を $10 \mathrm{~cm} / \mathrm{s} に$

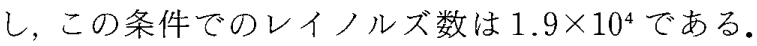
流速測定にはLDVを使用した。測定領域は図 1(c) で示すように物体の代表長さ $h$ に対して $0.075<$ $x / h<0.295$ ，および $0<y / h<0.225$ の範囲で行った.

なお，測定領域は事前の可視化観測によって特徵的 な現象が生じる領域を特定し，その領域のみ測定を行 うことで実験の効率化を図った。すなわち図1(c)の 左上角や右下角付近では測定を行っていない.

本実験では，物体剝離点の極近傍領域内において， 測定された時間平均速度分布から渦度, せん断変形速 度, 渦度消失割合およびレイノルズ応力を算出してそ れらの等高線図を作成し，可視化画像と比較すること で渦度の消失現象の考察を行った。式(1)〜（3)は， それぞれの算出に用いた計算式を示している。

渦度：

$$
\omega=\frac{\partial v}{\partial x}-\frac{\partial u}{\partial y}
$$

せん断変形速度：

$$
e=\frac{\partial v}{\partial x}+\frac{\partial u}{\partial y}
$$

渦度生成割合：

$$
\varepsilon=u \frac{\partial \omega}{\partial x}+v \frac{\partial \omega}{\partial y}
$$

渦度方程式：

$$
\begin{aligned}
& u \frac{\partial \omega}{\partial x}+v \frac{\partial \omega}{\partial y}=v\left(\frac{\partial^{2} \omega}{\partial x^{2}}+\frac{\partial^{2} \omega}{\partial y^{2}}\right) \\
& \text { レイノルズ応力: } \\
& \overline{u^{\prime} v^{\prime}}=\frac{r m s_{-}^{2}-r m s_{+}^{2}}{4 \cos 30^{\circ} \sin 30^{\circ}} \cdots \cdots .
\end{aligned}
$$

渦度生成割合は渦度抢上び速度データに基づいて微小 要素を通過する循環のバランスから二次元流れの単位 面積当たりの循環生成量として算出している.

式（4）は二次元層流に扔ける渦度方程式であるが, 式 ( 3 )の渦度生成割合は式 (4)の左辺と同じであり, 右辺の粘性作用によって洞度の生成と消失が起こるこ とを示唆している。またレイノルズ応力に関しては,

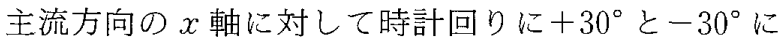
傾けて流速を測定し，別々に測定した速度の rms 值を それぞれ $r m s_{+}, r m s_{-}$として算出し, 式(5)を用いて 求めた。また可視化実験に当たっては，前述したよう に供試物体の中央部に設けた直径 $1 \mathrm{~mm}$ の色素流出 孔から蛍光のウラニン水溶液を流す色素流脈法を用い た. 撮影は $1 / 30 \mathrm{~s}$ 間隔で行い，可視化画像と速度デー 


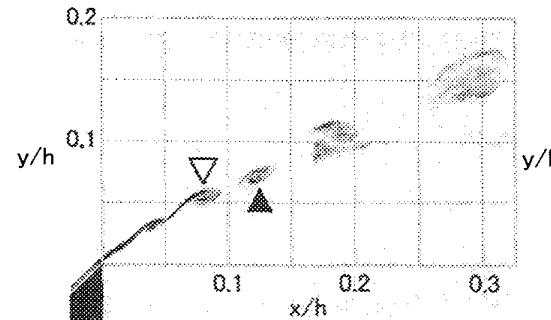

(a) $1 / 30 \mathrm{sec}$

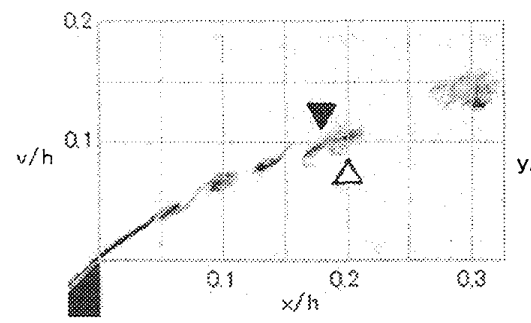

(d) $4 / 30 \mathrm{sec}$

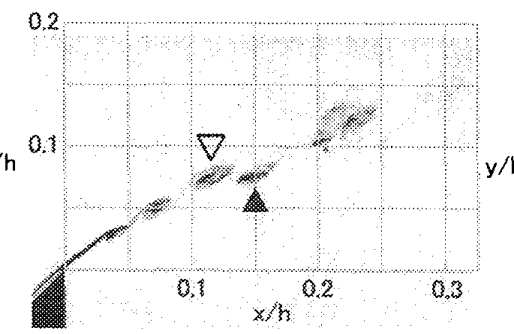

(b) $2 / 30 \mathrm{sec}$

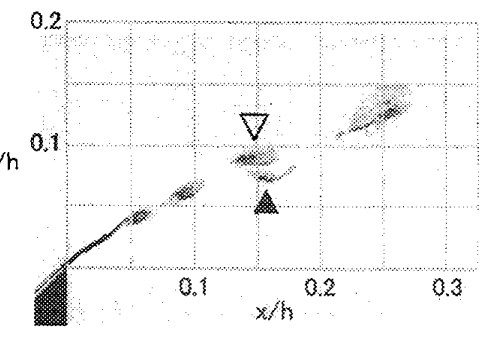

(c) $3 / 30 \mathrm{sec}$

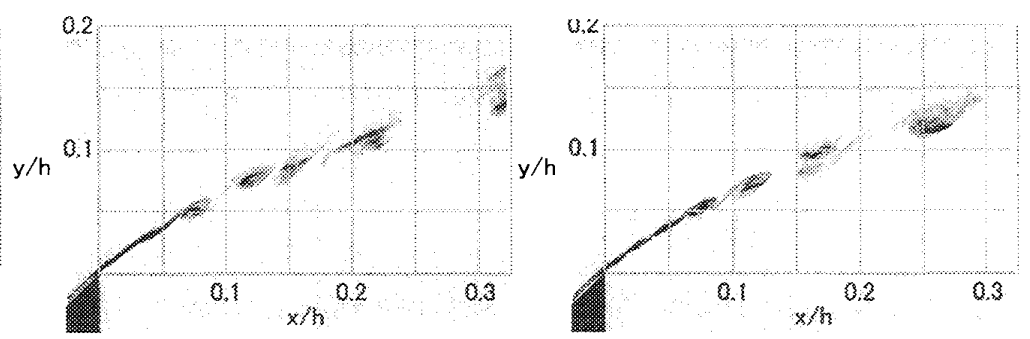

(e) $5 / 30 \mathrm{sec}$

(f) $6 / 30 \mathrm{sec}$

Fig. 2 Time series visualization photo

夕の分布を比較することによって考察を行った。

\section{3. 結果および考察}

$3 \cdot 1$ 物体後方の可視化 図 2 ばある時刻を基準

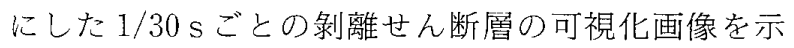
している. 図 2 中の薄い線で示すグリッドの格子間隔 は距離 $x$ または $y$ を物体の代表寸法 $h$ で無次元化し た無次元長さ 0.05 に対応している. またこの可視化 画像には大小いくつかの色素の塊が存在するが, 渦塊 には周囲の流体をエントレインする性質があるため, 本実験ではそ机ぞ机の色素塊を独立した渦塊と見な し，小さな塊を便宜上小洞と呼び，合体等で大きくな った渦塊を便宜上中渦と呼ぶことにした。図 2 におい て $1 / 30 \mathrm{~s}$ から $6 / 30 \mathrm{~s}$ まで時間を追って見てゅくと， 剝離せん断層沈いててルビン・ヘルムホルッの不安 定性に基づく小渦が次々と生成されているのが分か る。次に図2(a)の $1 / 30 \mathrm{~s}$ 加 (d)の4/30sにかけ て、抢よびムで指した小渦を時間を追って見てめく と, (a)の $x / h=0.1$ 付近に扔いて生成された小渦は, (c) $0 x / h=0.15$ 付近に達すると隣接する小渦と合 体を開始し, (d)の $x / h=0.2$ 付近で合体を完了して いることがわかる．したがって，この物体の剝離点の 極近傍における剝離せん断層に扔いては，小渦同士の 合体が生じる領域を境にその上流と下流では流れの特 性が大きく異なっているものと考えることができる. 一方, 物体の剝離点の上流では個体壁面があるため, 流机場は境界層流れであり，そこでは粘性作用によっ て渦度が形成されている。これに対して剝離点よりも

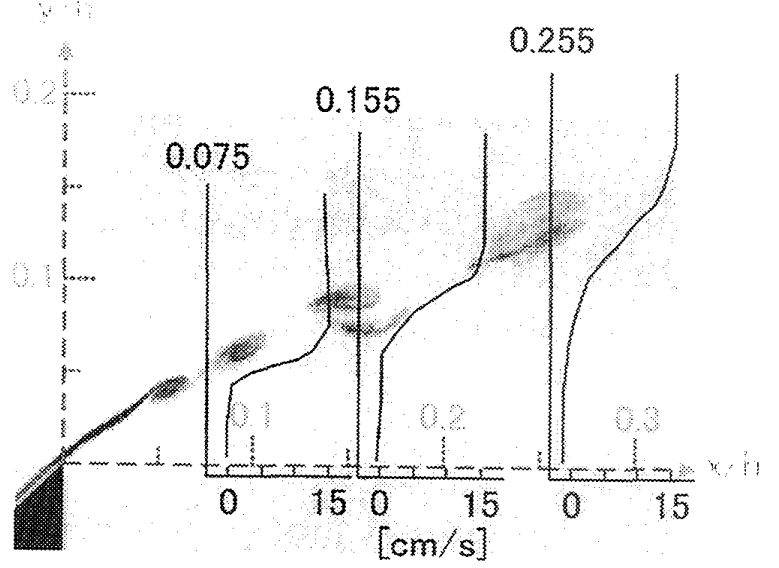

Fig. 3 Visualization photo and velocity distribution at each $x / h$ position when time is $3 / 30$ second

十分下流の恼離せん断層では壁面が無いために自由せ ん断流となっている．したがって本研究での測定領域 は速度分布が境界層的なものから自由せ几断流的なも のへと遷移する流机場であると予想され，以下はこの 遷移過程に扔ける粘性作用と渦度の挙動について述べ るものである。

3.2 速度分布 図 3 は $x / h=0.15$ 付近で, 小渦 同士の合体が抒き始めている時刻である，3/30s［図 $2(\mathrm{c})]$ に抢ける可視化画像 (以後 $3 / 30 \mathrm{~s}$ の画像と呼 ぶ) に $x / h=0.075,0.155,0.255$ それぞれの位置にお けるu方向の速度分布を重ねたものである. 図 3 の ように物体の剥離点に近い上流側の小渦が生成されて いる流れ場では速度ゼロ付近からの速度の立ち上がり が大きく，境界層流机に近い速度分布となっている。 


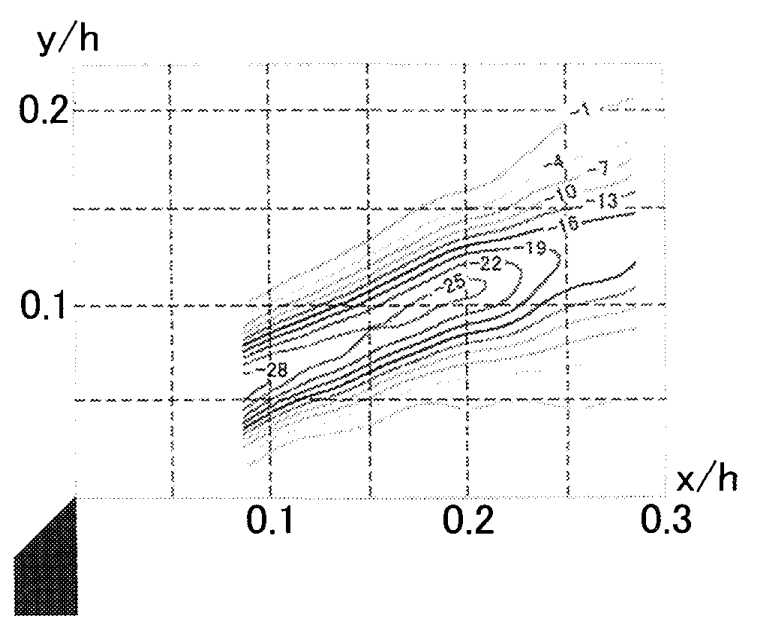

(a) Vorticity distribution

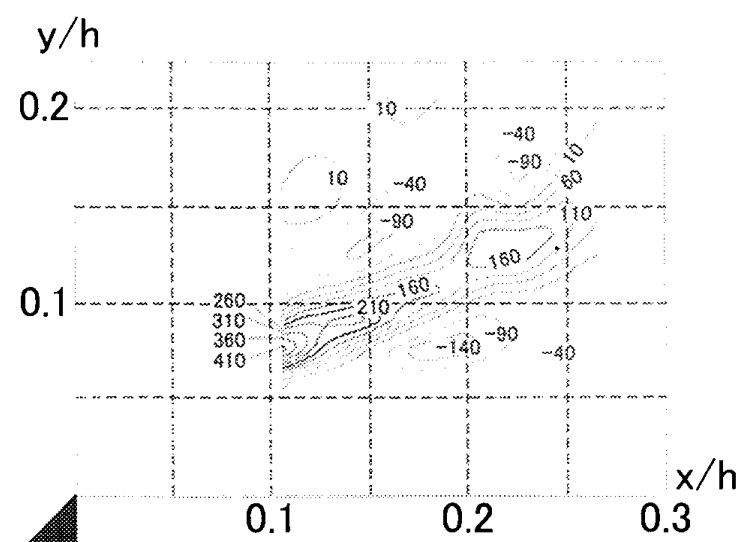

(c) Distribution of vorticity decay rate

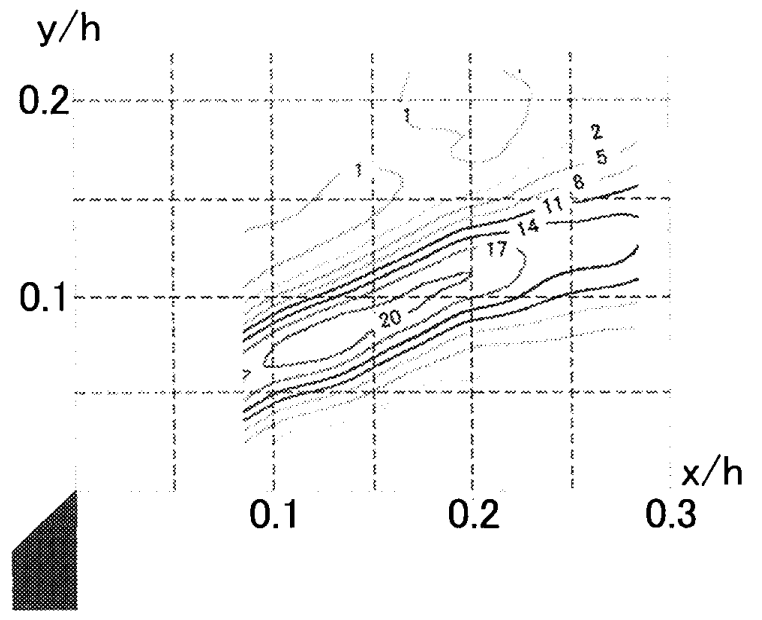

(b) Distribution of shear velocity
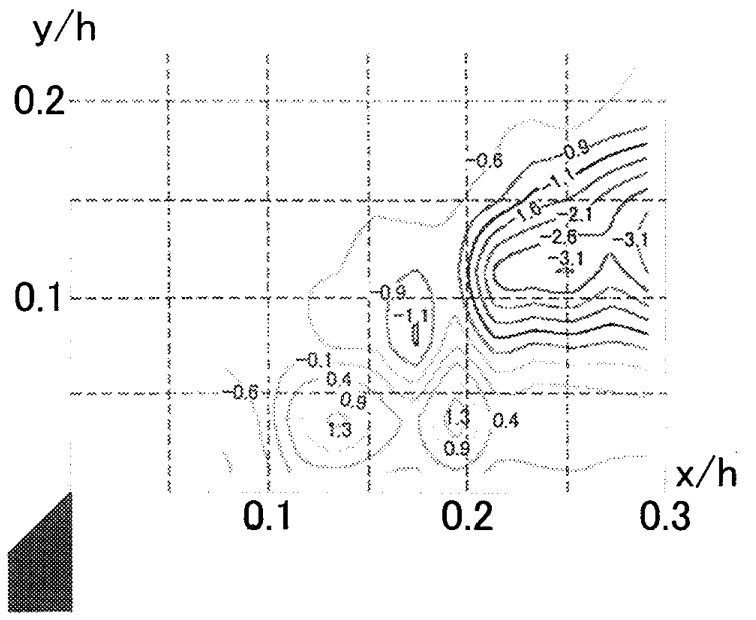

0.1

0.2

Fig. 4 Various contour lines

これに対し，それよりも下流の中渦が形成されている 流れ場 $(x / h=0.255$ 付近)では自由せん断流に近い速 度分布になっていることが分かる。したがって本测定 領域は小渦の合体に伴って剥離せん断層の速度分布が 境界愿的なものから自由せん断流的なものへの遷移領 域であることが分かる。

$3 \cdot 3$ 等高線図による考察 図 4 は時間平均速度 分布加算出された瀜度, せん断変形速度, 渦度消失 割合，およびレイノルズ応力の等高線図を示したもの である。

$3 \cdot 3 \cdot 1$ 渦度およびせん断変形速度図 5 は図 4(a)に抢ける渦度分布図に図2(c)の3/30s の可視 化画像での渦塊の㫻郭線を重ねたものである. また図 6 は図 4(a)に招ける渦度分布図に図 4(b) のせん断 変形速度分布図から代表的な等高線を抽出して破線で 示したものである。図 5 から $x / h=0.1$ 付近に打いて 渦度が最大值を示し, それより下流の $x / h=0.2$ 付近 までは渦度の減少は少なく, $x / h=0.2$ 付近を越える

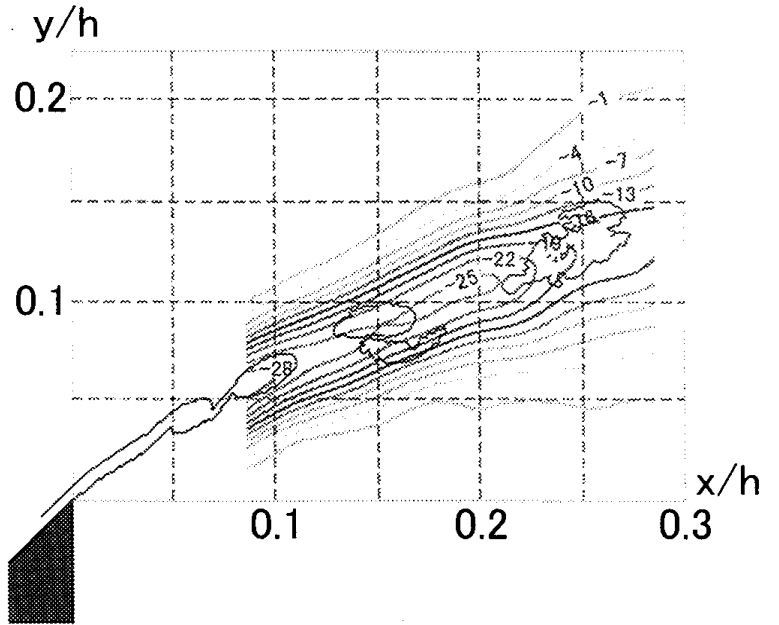

Fig. 5 Vorticity distribution with visualization picture when time is $3 / 30$ second

と渦度は急激に減少している。また図 6 に破線で示し たせん断変形速度分布にも同様な傾向が表机ている。 このことは剥離せん断層においては, 渦度の式(1)お 


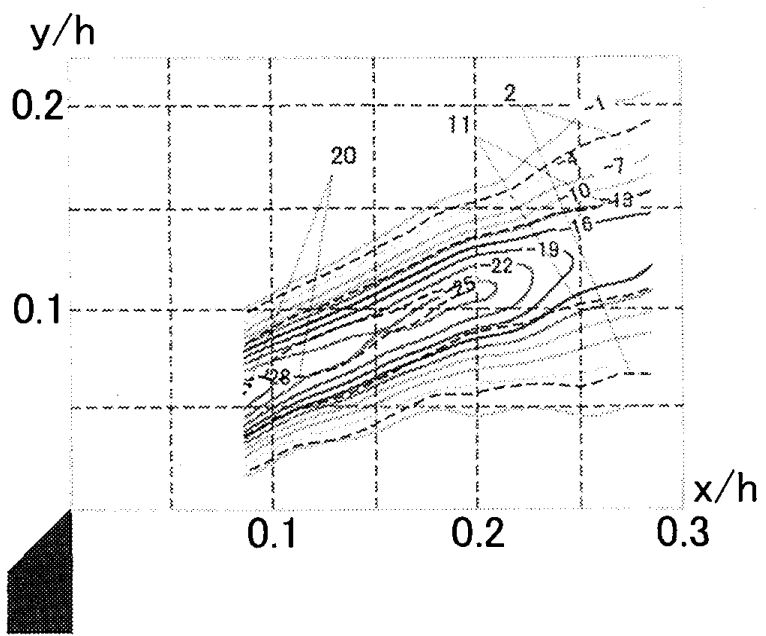

Fig. 6 Vorticity distribution with shear velocity (black dotted lines)

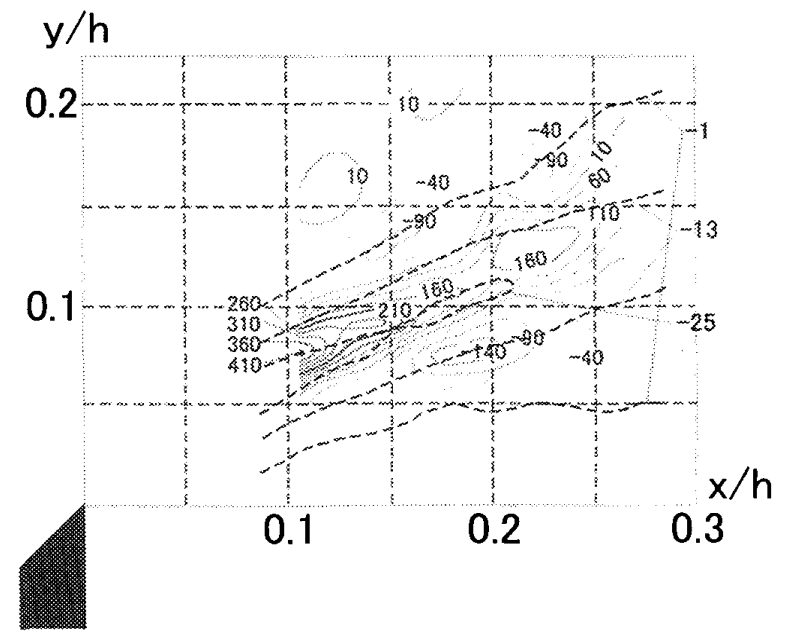

Fig. 7 Distribution of vorticity decay rate with vorticity (black dotted lines)

よびせん断変形速度の式 $(2)$ の $\partial u / \partial y$ が $\partial v / \partial x$ より もかなり大きいため $y$ 方向の速度勾配の減少が大き く寄与しているものと思われる.

$3 \cdot 3 \cdot 2$ 渦度消失割合図 7 と図 8 は渦度消失割 合 [図 4(c)］に渦度分布図 [図 4(a)］とせん断変 形速度分布図 [図 4(b)] をそれぞれ重称合わせたも のである。一方，渦度生成割合は正の值の時には生成 を, 負の時には消失を表すが, 本研究で用いた座標系 の関係で剝離せん断層に放出される渦度は負の渦度 (時計回り)であるため, 渦度生成割合が正の時には負 の渦度が減少し, 生成割合が負の時には負の渦度が増 加する。そのため本研究では, 渦度生成割合を渦度消 失割合と読み替えることにする。

図 7 抢よび図 8 のいずれにおいても渦度の消失割合 の大きい領域は, 渦度とせん断変形速度が大きい領域

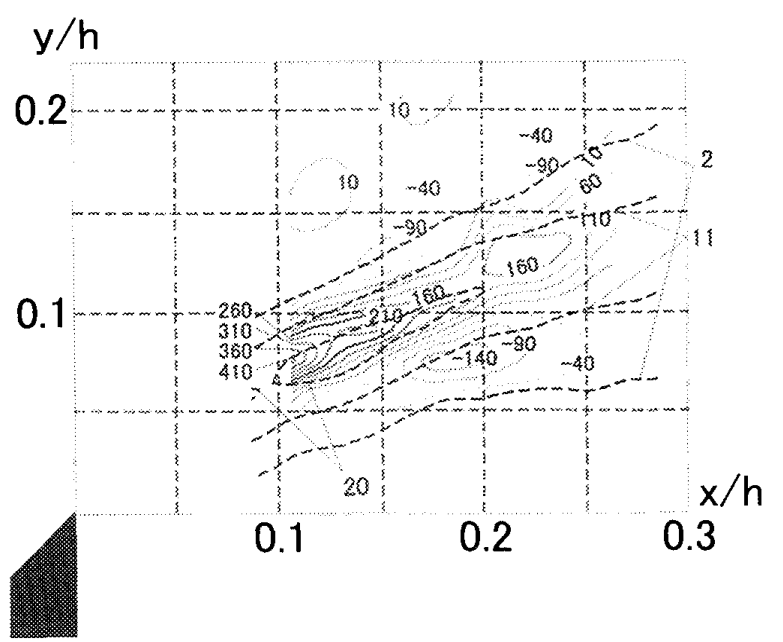

Fig. 8 Distribution of vorticity decay rate with shear velocity (black dotted lines)

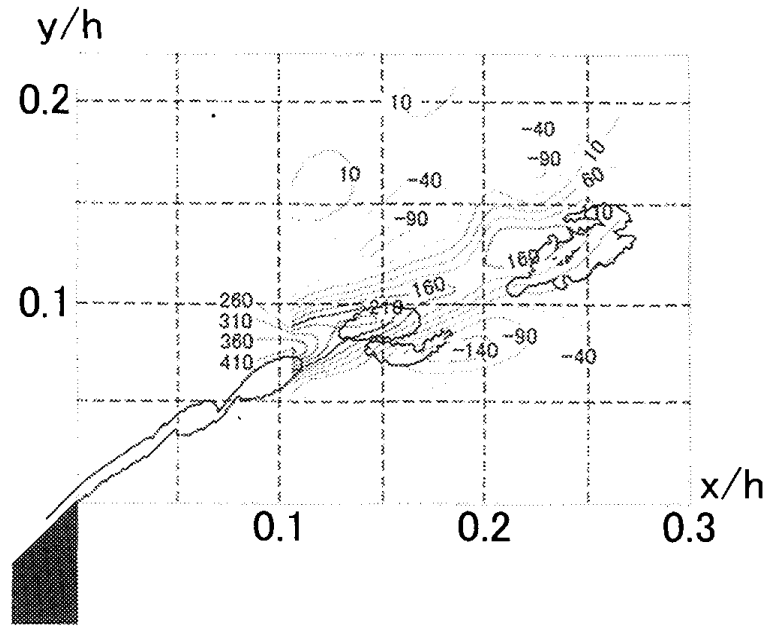

Fig. 9 Vorticity decay rate distribution (grey lines) and visualization picture when time is $3 / 30 \mathrm{sec}$ ond

である。図 3 で示しているように速度分布が境界層的 な性質を持ったものから自由せん断流的なものへ遷移 する時の粘性作用がせん断変形を生じさせ，渦度の消 失を生じさせているものと考えられる。特に図 3 の $x / h=0.255$ では速度分布がほぼ自由せん断流のよう になって扝り，この付近で渦度の消失もほぼ収まって いる. Mair-Maull ら ${ }^{(3)}$ は鈍い物体からのカルマン渦 の放出における大きな渦度の消失は物体のもう一方の 剝離せん断層に放出された異符号の渦度との相殺によ って起き，物体の十分下流における渦の循環は小さく なると述心ている。しかし，本研究の結果から物体の 極近傍に执いては速度分布の遷移過程に伴う粘性作用 によっても渦度の消失が起こっていることが分かる。

一方図 7 と図 8 において $x / h=0.2$ 付近では渦度お よびせん断変形速度の尾根の下側に渦度が生成されて 


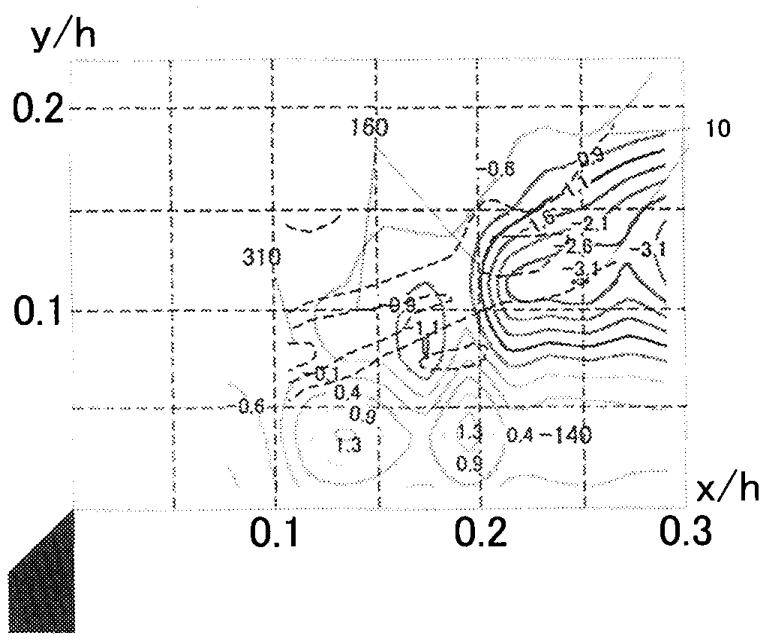

Fig. 10 Reynolds stress distribution and vorticity decay rate (black dotted lines)

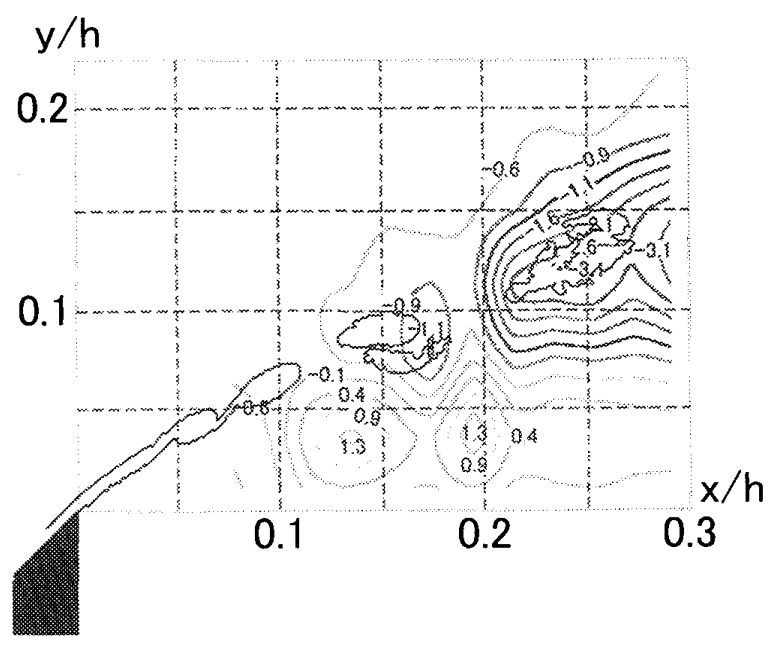

Fig. 11 Reynolds stress distribution and visualization picture when time is $3 / 30$ second (gray lines)

いる領域が局所的に存在しているのがわかる. そこ で，図 9 に3/30sにおける可視化画像と渦度消失割合 の分布を重ねたものを示した，図 9 から，渦度が局所 的に生成されている付近では小渦が合体する過程にあ り，下側の渦がストレッチされながら渦度が生成され ている領域を通過してゆくのがわかる。したがって， この渦度の局所的な生成は下側の小渦のストレッチに 伴う粘性作用によるものと考えることができる。

$3 \cdot 3 \cdot 3$ レイノルズ応力 レイノルズ応力は乱流 拡散の度合を知る上で重要なパラメータである。一 方，二次元物体である円柱からのカルマン渦放出では， 低いレイノルズ数で見られる自然渦転移(10) で代表さ れる流れの三次元性が良く知られている。本研究での 剥離せん断層に扔ける代表寸法はケルビン・ヘルムホ ルツの不安定性によって生じている小渦の直径程度で
あり, 剥離せん断層内のレイノルズ数は小さいと考え ることができ,レイノルズ応力を指標とした乱流搪散 による擾乱と流れの不安定性によって三次元化が進み やすいものと考えることができる、したがって本研究 でここまで示してきた渦度の消失が乱流拡散によるも のか否かを明らかにすることは重要である。そこで図 10 にはレイノルズ応力の分布眓と渦度消失割合の分 布図を重㸚わせたものを示し，図11にはレイノル ズ応力の分布図と3/30sにおける可視化画像を重衫 合わせたものを示している. 図 10 より $x / h=0.1$ か ら 0.2 付近における渦度の消失が最も顕著に起こって いる領域ではレイノルズ応力は小さく, 流れの乱流化 が進んでいないことが分かる。一方, 図 11 から分か るように小渦の合体が完了する $x / h=0.25$ 付近にお いてはレイノルズ応力は非常に大きくなっている。し たがって合体した中渦は乱れとともに三次元的な流れ 構造を持っているものと考えられる。

\section{4. 結 論}

以上の実験結果から剝離せん断層に扔ける渦度の消 失について以下のような結論が得られた。

（1）物体背後の剥離せん断層における渦度の消失 は，異符号の渦度との相殺作用の他に，剥離点極近傍 の剥離せん断層の速度分布が境界層的な分布から自由 せん断流的な分布へ遷移することに伴う粘性作用によ っても起こることが分かった。

（2）小渦の合体が開始する付近においては，合体 に伴うストレッチによって, 局所的に渦度が生成され ることが分かった。

（3）物体の剥離点の極近傍における渦度の消失に は, 乱流拡散に伴うレイノルズ応力が直接関与してい ないことが分かった。

（4）小渦が合体して生成された中渦付近において はレイノルズ応力が大きいことから, 合体によって流 れ場の乱流化と三次元化が進むことが分かった。

本研究において，実験装置の作製などにご協力いた だいた北見工業大学技術部の小畑芳弘技術員に謝意を 表する。

\section{文献}

(1) Gerrard, J.H., The Mechanics of the Formation Region of Vortices behind Bluff Bodies, Journal of Fluid Mechanics, Vol. 25, No.2 (1966), pp. 401-413.

(2) Sarpkaya, T. and Schoaff, R. L., Inviscid Model of Two-Dimensional Vortex Shedding by a Circular Cylinder, American Institute of Aeronautics and Astronautics Joumal, Vol. 17, No.11 (1979), pp.11931200. 
(3) Mair, W. A. and Maull, D. J., Bluff Bodies and Vortex Shedding-A Report on Euromech 17, Journal of Fluid Mechanics, Vol. 45, No. 2 (1971), pp. 209-224.

(4) Luo, S.C., Tong, X. H. and Khoo, B.C., Transition Phenomena in the Wake of a Square Cylinder, Joum al of Fluids and Structures, Vol.23, Issue 2 (2007), pp. 227-248.

(5) Tong, X.H., Luo, S.C. and Khoo, B. C., Transition Phenomena in the Wake of an Inclined Square Cylinder, Joumal of Fluids and Structures, Vol. 24, Issue 7 (2008), pp. 994-1005.

(6) Wang, X. K. and Tan, S. K., Near-Wake Flow Characteristics of a Circular Cylinder Close to a Wall, Journal of Fluids and Structures, Vol.24, Issue 5 (2008), pp. 605-627.

( 7 ) Downes, K. and Rockwell, D., Oscillations of a Vertical Elastically Mounted Cylinder in a Wave: Imaging of Vortex Patterns, Journal of Fluids and Structures,
Vol. 17, Issue 7 (2003), pp. 1017-1033.

(8) Haniu, H., Sakamoto, M., Matsuda, M. and Obata, Y. Transitional Characteristics of Separated Shear Layer in the Vortex-Generating Region Behind a Body (Correspondence Between Image of Flow Visualization and Velocity Fields Obtained by LDV Measurement at the Same Phase), Transactions of the Japan Society of Mechanical Engineers, Series B, Vol. 62, No. 594 (1996), pp. 620-627.

(9) Haniu, H., Sakamoto, H. and Dogan, Y., Transitional Characteristics of Flow in a Vortex-Generating Region Behind a Body by Means of LDV, Transactions of the Japan Society of Mechanical Engineers, Series B, Vol. 59, No. 567 (1993), pp. 3303-3307.

(10) Williamson, C. H. K., The Natural and Forced Formation of Spot-Like 'Vortex-Dislocation' in the Transition of a Wake, Joumal of Fluid Mechanics, Vol. 243 (1992), pp. 393-441. 